\title{
Erratum to: Dualists needn't be anti-criterialists (nor should they be)
}

\section{Matt Duncan ${ }^{1}$}

\section{Erratum to: Philos Stud DOI 10.1007/s11098-016-0715-2}

Unfortunately, the corresponding author's name has been misspelled in the original publication. The correct name is "Matt Duncan".

The original publication has also been updated.

The online version of the original article can be found under doi:10.1007/s11098-016-0715-2.

Matt Duncan

s.matthew.duncan@gmail.com

1 Rhode Island College, Providence, RI, USA 